\title{
Paid work, household work, or leisure? Time allocation pathways among women following a cancer diagnosis
}

\author{
Gao, $\mathrm{Ni}^{1}$, Ryan, Mandy ${ }^{1}$, Krucien, Nicolas ${ }^{1}$, Robinson, Suzanne ${ }^{2}$, Norman, Richard ${ }^{2}$
}

1. Health Economics Research Unit, Institute of Applied Health Sciences, University of Aberdeen, Polwarth Building, Aberdeen AB25 2ZD, UK.

2. Health Systems and Health Economics, School of Public Health, Curtin University, Perth, Australia

\begin{abstract}
Background: There is extensive evidence on the relationship between receiving a cancer diagnosis and labour market outcomes. However, there is limited evidence on the relationship between a cancer diagnosis and non-labour market outcomes such as household work, passive leisure and physical leisure. Furthermore, most current research focuses on time allocation at a given time point, ignoring both the life course perspective and long term effects.

Methods: Using data from the Australian Longitudinal Study on Women's Health (ALSWH), we observe time allocation for 91 women diagnosed with breast cancer and 486 women diagnosed with skin cancer, and 2,711 women living without cancer. Our analysis is unique in combining sequence analysis and multivariate multinomial logit modelling. Using sequence analysis, we first analyse life-courses post a cancer diagnosis for paid work, household work, passive leisure and physical leisure from 2004 to 2016. Using multivariate multinomial logit modelling, we test whether a cancer diagnosis influences such life-courses. We consider the robustness of results to cancer severity and change in time allocation before and after a cancer diagnosis.

Results: We identify three clusters for paid work and two clusters for household work, passive leisure and physical leisure. Neither a breast cancer nor skin cancer diagnosis has a significant effect on the pathways of time allocation. Such results are robust to severity of diagnosis with 'cured' and 'non-cured' breast cancer, and skin cancer treated with and without 'chemotherapy or radiotherapy'. Women post a breast cancer diagnosis are less likely to maintain their precancer's time use on paid work, household work and passive leisure; however, such effects are not significant.
\end{abstract}

Conclusion: Being diagnosed with breast cancer or skin cancer has no significant long-term effect on the pathways of time allocation. Future work should explore the relationship between time allocation and wellbeing and the preference for time allocation. 


\section{Introduction}

Time, scarce and irreversible, is regarded as having considerable economic value (Caragea, 2009). As a key component of welfare, time use contributes to a broader understanding of the distribution of economic returns(Hamermesh \& Pfann, 2004). There is extensive evidence on the relationship between a cancer diagnosis and labour market outcomes (Kiasuwa Mbengi et al., 2016). However, there is limited evidence on the relationship between a cancer diagnosis and non-labour market outcomes, such as household work and leisure. Understanding how individuals, post a cancer diagnosis, allocate their time on labour market and non-labour market activities has important economic implications. Firstly, time allocation across daily activities may be a reliable indicator of recovery. Although return to work is often considered to be a signal of physical recovery (Cathy J Bradley, 2015; Hewitt, Greenfield, \& Stovall, 2005; Maunsell, Brisson, Dubois, Lauzier, \& Fraser, 1999; Pryce, Munir, \& Haslam, 2007), it may not be a robust indicator as some individuals are compelled to work at excessively high levels due to financial concerns or other obligations. Focusing on return to work alone also fails to account for the situation when individuals return to work but leave other daily activities unfinished due to limited health. Broad recovery should refer to reintegration into daily activities, including both labour market and non-labour market activities. Secondly, social reintegration following a cancer diagnosis is not a simple return to pre-cancer status (Mackenzie, 2014). Changes in individuals' preferences and life perspectives due to a cancer diagnosis may change their priorities in the areas of health, work and other daily activities. This can be reflected by how individuals re-allocate their time across daily activities. Time re-allocation following a cancer diagnosis therefore may imply a new optimization on lifetime utility and may further imply a new economic return to personal welfare, household welfare and even national welfare. 
Despite the important role of health on time allocation, few studies have examined the relationship between time allocation and health. To the best of our knowledge, only four studies have investigated time allocation and general health status(Gimenez-Nadal \& Molina, 2015, 2016; Gimenez-Nadal \& Ortega-Lapiedra, 2013; Podor \& Halliday, 2012). Results indicate better health is associated with more time spent on paid work and less time on nonlabour market work (e.g. household production). However, these studies focus on the general population (rather than individuals experiencing health issues). Other studies examine time allocation among disabled individuals with a mental illness, cord injury, schizophrenia, or traumatic brain injury(Leufstadius \& Eklund, 2008; Lomax, Brown, \& Howard, 2004; Pagán, 2013; Pentland, Harvey, Smith, \& Walker, 1999; Shimitras, Fossey, \& Harvey, 2003). However, results may not generalize to individuals experiencing a cancer diagnosis. Moreover, those studies are mainly based on cross-sectional data rather than longitudinal data.

This paper contributes to the literature in several ways. First, it explores the impact of a cancer diagnosis on time allocation across daily activities. Second, in contrast to previous literature where time allocation is revealed at a given time point, it uses longitudinal data to investigate time allocation from a life course perspective. The adjustment of time allocation due to a cancer diagnosis may not happen instantaneously but last over a period of months, years and may even be life-long. We map out the 'trajectories' of time allocation following a cancer diagnosis. The 'trajectories' of time allocation can answer whether time allocation changes after a cancer diagnosis as well as when such change happens and how long it lasts. Third, the effect of a cancer diagnosis on time allocation has been looked at in the short-term (e.g. 6 to 12 months post a cancer diagnosis) (Cathy J Bradley, Neumark, Bednarek, \& Schenk, 2005; Cathy J Bradley, Neumark, Luo, \& Schenk, 2007; David Candon, 2015) or mid-term (e.g. 2 to 7 years post a cancer diagnosis) (C. J. Bradley, Bednarek, \& Neumark, 
2002; Cathy J Bradley et al., 2005; Cathy J Bradley et al., 2007; D. Candon, 2015; Sung Hee Jeon, 2014; Sung-Hee Jeon, 2016; Moran \& Short, 2014; Moran, Short, \& Hollenbeak, 2011). Our study, by observing the 'trajectories' of time allocation over 12 years following a cancer diagnosis, investigates the longer term effect of cancer on time use. We hypothesize that being diagnosed with a cancer at a given stage of life course may have 'cumulative disadvantages' that result in further disadvantages throughout the life course (Dannefer, 2003; Hoven, Dragano, Blane, \& Wahrendorf, 2017). That is, cancer induced 'cumulative disadvantages' may influence time allocation in a gradual and longitudinal manner over the life span.

The paper is organized as follows. Section 2 describes the data and measures. Section 3 describes the empirical analysis and Section 4 shows the results. Section 5 considers the robustness of results to severity of cancer and the change in time allocation before and after a cancer diagnosis. Section 6 discusses the results, limitations of our study, and areas for future research.

\section{Data and Measures}

\subsection{Australian Longitudinal Study on Women's Health (ALSWH)}

We used the longitudinal population-based survey from the Australian Longitudinal Study on Women's Health (ALSWH). ALSWH provides comprehensive data on health and wellbeing throughout a woman's lifespan (Young et al., 2005). ALSWH was approved by the Australian Government Department of Health Human Research Ethics Committee and the Human Research Ethics Committees at the University of Queensland and the University of Newcastle. The informed consent was received from all participants and the data are openly available. 
From 1996, women in three age groups were surveyed every three years. These cohorts were those born between 1973 and 1978 (aged 18-23 years old in 1996), between 1946-1951 (4550 years old) and between 1921 and 1926 (70-75 years). We focused on the middle-aged category women (born in 1946-51) as only this cohort contains information on both time use and cancer types. As time use information is only available from Wave 3, we observed women from Wave 3 to 8 (year 2001 to 2016), following women from 50 years old (the youngest in 2001) to 70 years old (the oldest in 2016).

We focused on women diagnosed or treated with cancer before age 55 (Waves 3 and 4). We observed their pathways of time allocation after age 55 (Waves 4 to 8). We chose age 55 as the cut-off point because cancer incidence begins to increase from age 50 to 55(Australia Bureau of Statistics, 2019). We included women who reported being diagnosed or treated with breast cancer or skin cancer in Wave 3 or 4 (between age 47 to age 55), based on the questions: "In the past three years, have you been diagnosed with or treated for [cancer]?" We also included women without a cancer diagnosis throughout the observed waves as the control group. We excluded women: i) who were diagnosed or treated with cancer beyond age 55 (being diagnosed with cancer after the realisation of pathways of time allocation would lead to the problem of anticipatory analysis that may contaminate causality (Hoem \& Kreyenfeld, 2006); ii) whose total weekly time use on all daily activities was either zero or more than 168 hours; iii) and those lost to follow-up.

Our final dataset consisted of 3,288 women, of which 2,711 (82.45\%) women reported having no cancer diagnosis in all waves, $91(2.77 \%)$ women were diagnosed with breast cancer before age 55, and $486(14.78 \%)$ women were diagnosed with skin cancer before age 55. 


\subsection{Measures of daily activities}

We considered four types of daily activities: paid work, household work, passive leisure (for example, watching TV, listening to music, reading, and general relaxing) and physical leisure. Time use on paid work, household work, and passive leisure were based on responses to the question: "In a usual week, how much time in total do you spend doing the following things?" Response categories were: 1. I don't do this activity; 2. 1-15 hours; 3.16-24 hours; 4. 25-34 hours; 5. 35-40 hours; 6. 41-48 hours; 7. 49 hours or more. Detailed questions are listed in Supplementary Table A1.

We identified three mutually exclusive types of paid work: i) Full time paid work (working more than 35 hours in full-time paid work and casual full-time paid work); ii) Part time paid work (working 1-34 hours in part-time paid work and casual part-time paid work); and iii) Unemployment: not in labour force (for example, unable to work or retired) and unemployed (looking for and available for work). This classification was based on Australia Bureau of Statistics for labour force participation(Australian Bureau of Statistics, 2001).

Regarding household work (own/family home duties), we combined the categories with low percentages (percentages of time use in the category of 0 hours, 1-15 hours, 16-24 hours, 2534 hours, 35-40 hours, 41-48 hours and 49 hours or more were 2.21, 49.25, 21.53, 12.33, 6.12, 2.39, and 6.17, respectively), and identified two levels of intensity: (i) $\leq \mathbf{1 5}$ hours per week, and (ii) >15 hours per week.

Like household work, we identified two levels of intensity for passive leisure: (i) 1-15 hours per week, and (ii) More than 15 hours per week (percentages of time use in the categories of 1-15 hours, 16-24 hours, 25-34 hours, 35-40 hours, 41-48 hours and 49 hours or more were $60.80,21.12,9.12,3.5,1.37$ and 1.64 , respectively). 
Physical leisure was based on responses to the question: "If you add up all the times you spent in each activity last week, how much time did you spend altogether doing each type of activity?" One of the activities corresponding to vigorous physical activity (that makes you breathe harder or puff and pant like aerobics, competitive sport, vigorous cycling, running, swimming) was used as a proxy for physical leisure. We identified four levels of intensity: i) Zero (do not do this activity); ii) Low ( $<1.25$ hours per week); iii) Moderate $(\geq 1.25$ and $<2.5$ hours per week); and iv) Intensive ( $\geq 2.5$ hours per week). This classification was based on World Health Organization guideline on vigorous physical activity "at least at least 75 minutes of vigorous-intensity aerobic physical activity throughout the week; or 150 minutes for additional health benefit"(World Health Organization (WHO), 2010.).

\subsection{Descriptive summary of longitudinal data}

Table 1 summarizes time allocation and social-economic characteristics of respondents by wave. The upper panel shows the percentages of time allocation on each defined level for the four daily activities. Regarding paid work, the percentage of unemployment increased from $19 \%$ in Wave 3 to $69 \%$ in Wave 8 , accompanied by a steady decrease in full time work, from $45 \%$ in Wave 3 to $8 \%$ in Wave 8. Regarding household work, the percentages in both levels were relative stable during the observed waves. The percentage of passive leisure in the level of '1-15 hours per week' decreased with waves, accompanied by an increase in the level of '>15 hours per week'. Regarding physical leisure, in each wave, over 70\% women did not participate in physical leisure. The lower panel shows socioeconomic characteristics of respondents: percentage of marriage shows a decrease trend; health indictors such as SF-6D and general health were relatively stable; the number of diseases increased with waves; and $70 \%$ women did not provide caregiving in each wave. 


\section{Table 1. Time allocation and socioeconomic characteristics by Wave}

[Insert here]

Figure 1 illustrates the trends of time allocation on paid work, household work, passive leisure and physical leisure from Wave 3 to Wave 8 (hours of time use on four daily activities were calculated by replacing interval values with the midpoint). Time use on paid work dropped dramatically. This is because most women reached retirement age in 2013 (62-67 years old) and 2016 (65-70 years old). Time use on passive leisure increased slightly over the years. Time use on household work and physical leisure were relatively stable.

Figure 1. The trends of time allocation from wave 3 to 8

[Insert here]

\section{Empirical analysis}

\subsection{Sequence Analysis: defining post-cancer diagnosis pathways of paid work, household} work, passive leisure and physical leisure

A sequence (pathway) is an ordered list of daily activities from Wave 4 to Wave 8 . Take an example of paid work, suppose a woman was diagnosed with cancer at Wave 3, her paid work status was recorded at each wave after Wave 3. This could be full-time paid work (F) from Wave 4 to 6 , followed by unemployed (U) from Wave 7 to 8 . A sequence of this woman is recorded as "F-F-F-U-U". Each woman generates a sequence; some may have the same sequences. We identified 152 unique sequences for paid work, 32 for household work, 32 for passive leisure, and 502 for physical leisure, respectively. 
Figure 2 shows the ten most frequent sequences of daily activities. Panel A. shows the sequences of paid work and household work and Panel B shows the sequences of passive leisure and physical leisure. The y-axis indicates the cumulative percentage of the ten most frequent sequences. The y-axis and the sequences are displayed bottom-up: the sequences are sorted by the frequency with the first ranked sequence (the most common sequence) at the bottom of the plot. The ten most frequent sequences account for $53 \%$ of all trajectories for paid work, $65 \%$ for household work, $66 \%$ for passive leisure and $57 \%$ for physical leisure, which indicate sequences have relative low diversity. The most common sequences (green bar in the bottom) for each daily activity are: 'unemployment' for paid work; ' $\leq 15$ hours per week' for household work; '1-15 hours per week' for passive leisure; and 'zero' hours for physical leisure.

\section{Figure 2. Sequence frequency plots on daily activities}

[Insert here]

To assess the (dis)similarity of sequences, we used Optimal Matching (OM) to generate a distance matrix for each pair of individuals (whilst there are other distance measures (Studer \& Ritschard, 2016), OM is the most common method). OM is defined as the minimal cost of transforming one sequence into another (Gabadinho et al., 2009). The (dis)similarity of sequences is calculated as the number of operations needed to convert one sequence to another. As our sequences have equal length, the only possible operation was replacement. Following standard practice (Gabadinho et al., 2009), we set substitute costs to 2 (data-driven substitute cost is an alternative method. In our data, results based on data-driven substitute matrix are similar to setting substitute cost to 2). For instance, comparing two sequences of paid work from wave 4 to wave 8: 'F-F-F-F-U' and 'F-F-F-U-U', their dissimilarity comes from wave 7 (F compared to U). To transfer 'F-F-F-F-U' to 'F-F-F-U-U' (or vice versa), one 
replacement is required. The distance between those two sequences is numbers of substitution multiplied by substitution cost i.e. 2 is this example. Applying the same logic to the whole sample, we created a (dis)similarity matrix that contains distance for each pair of sequences.

\subsection{Cluster Analysis: grouping the pathways of paid work, household work, passive leisure} and physical leisure

We used cluster analysis to group similar sequences based on the (dis)similarity matrix. This approach first assigns each sequence as one cluster and merges the nearest clusters until all similar sequences belong to the same cluster (Anyadike-Danes \& McVicar, 2010). We adopted the Partitioning Around Medoids (PAM) clustering algorithm, with initial values obtained from the results of a hierarchical method. The algorithm of PAM is dependent on the initial choice of medoids, which is not always optimal (Studer, 2013). Instead, the initial value obtained from hierarchical clustering can overcome this limitation (Studer, 2013). The combined methods have the advantage of optimizing a global criterion (Studer, 2013). We use wcKMedoids function in R's WeightedCluster package (Studer, 2013) to perform the algorithms.

To select the best appropriate number of clusters, we compared a 2 to 5 cluster solution based on the measurements of cluster quality (Studer, 2013): Average Silhouette Width (ASW) (Kaufman \& Rousseeuw, 2009), Point Biserial Correlation (Hennig \& Liao, 2010), and Hubert's Gamma (Hubert \& Arabie, 1985). Generally, the higher values of those measurements indicate higher similarity within one group and higher dissimilarity between groups. Results of the measures are presented in Supplementary Table A2.

Table 2 summarizes the clusters of daily activities. We identified three clusters for paid work, and two clusters for household work, passive leisure and physical leisure. For paid work, Cluster 1 is characterized by women who were unemployed from Wave 4 to 8; Cluster 2 is 
represented by women who performed full time work from Wave 4 to 6 , followed by part time work in Wave 7 and unemployment in Wave 8; and Cluster 3 is characterized by women who performed part time work for the first three waves, followed by unemployment in the last two waves. For household work, Cluster 1 is represented by women who spent time on household work ' $\leq 15$ hours per week'; and Cluster 2 is represented by women who spent time on household work ' $>15$ hours per week'. For passive leisure, Cluster 1 is characterized by women who spent passive leisure ' $1-15$ hours per week'; and Cluster 2 is characterized by women who spent passive leisure ' $>15$ hours per week'. For physical leisure, Cluster 1 is dominated by women who never participated in physical leisure; and Cluster 2 is dominated by women who performed moderate to intensive physical leisure.

\section{Table 2. Distribution of clusters among four daily activities}

[Insert here]

Figure 3 illustrates the distribution of clusters by non-cancer, breast cancer and skin cancer. $39 \%$ of women diagnosed with breast cancer were in Cluster 2 of paid work, higher than women living without any cancer diagnosis and women diagnosed with skin cancer. Similar, $62 \%$ of women diagnosed with breast cancer were in Cluster 2 of household work, higher than other two groups. The distribution of clusters in passive leisure and physical leisure was similar across the three groups.

\section{Figure 3. Distribution of clusters among non-cancer group, breast cancer group and skin cancer group}

[Insert here]

\subsection{Multivariate Multinomial logit regression: predicting cluster membership}


We used the baseline characteristics at age 50-55 (Wave 3) to predict cluster membership. The key interest variable is whether women had been diagnosed with breast cancer or skin cancer. The control group is women living without cancer.

Given the fixed time budget constraint, time spent on one activity will be at the cost of time spent on other activities (Dahm et al., 2015). Decisions regarding time allocation across paid work, household work, passive leisure and physical leisure are thus simultaneously correlated. To allow for this we applied a multivariate multinomial logit (MV-MNL) model to predict cluster membership. This model is in the same spirit as the seemingly unrelated regression model in linear regression, except that the dependent variables are categorical indicators (Bel \& Paap, 2014).

In brief, for the MV-MNL model, the conditional probability for the $\kappa$-th choice given all other choices $y_{i l}$ is:

$$
\operatorname{Pr}\left[y_{i k}=j \mid y_{i l} \text { for } l \neq k, X_{i}\right]=\frac{\exp \left(Z_{i k, j}\right)}{\sum_{l=1}^{J_{k}} \exp \left(Z_{i k, l}\right)}
$$

We have four multinomial choices: paid work, household work, passive leisure and physical leisure $(\kappa=4)$. Each multinomial choice has $J_{k}$ potential outcomes. We have three clusters for paid work, and two clusters for the other three. $y_{i k}=j$ indicates individual i chooses $\mathrm{j}=1, \ldots, J_{k}$ for $\kappa$-th choice.

Where $Z_{i k}$ is

$$
Z_{i k, j}=\alpha_{k, j}+X_{i} \beta_{k, j}+\sum_{i \neq k} \theta_{k l, j y_{i l}}
$$

Where $\alpha_{k, j}$ are alternative and choice specific intercepts, $X_{i}$ is a vector of explanatory variables, including cancer indicator, age, martial, education, SF-6D, general health, number 
of chronic diseases, whether providing care, number of people living with (shown in Table 1, wave 3).

$\theta_{k l, j y_{i l}}$ is the association parameters between $k$-th choice and $l$-th choice. For instance, $\theta_{k l, j h}$ represents the association between choosing $j$ for $k$-th choice and $h$ for $l$-th choice. In our case, it indicates the association between choices on the pathways of paid work, household work, passive leisure and physical leisure.

To identify the parameters, we imposed standard identification restriction: $\alpha_{k, 1}=0$ and $\beta_{k, 1}=$ 0 for all $k$. Following Bel \& Paap (2014), we also imposed a symmetry restriction on the association parameters: $\theta_{k l, j h}=\theta_{l k, h j}$ for all $j$ and $h$. Since utility difference determines choice, not all association parameters can be identified. We therefore constrained $\theta_{k l, j 1}=$ $\theta_{l k, 1 h}=0$ for all $j$ and $h$.

\section{Results}

\subsection{Association between cancer indicators and pathways of time allocation}

Table 3 shows the impact of a cancer diagnosis on the pathways of time allocation across four daily activities. In general, being diagnosed with breast cancer or skin cancer before age 55 has no significant impact on the pathways of time allocation on paid work, household work, passive leisure and physical leisure in the long-term.

Specifically, relative to Cluster 1 in paid work (unemployment), being diagnosed with breast cancer increases the likelihood of following the pathway of Cluster 2 (full time paid work followed by part time paid work and unemployment) and the pathway of Cluster 3 (part time paid work followed by unemployment). The odds of following the pathways of Cluster 2 and Cluster 3 are 1.198 and 1.320 times greater in women living with breast cancer diagnosis than 
it is in women living without any cancer diagnosis. Similar, being diagnosed with skin cancer increases the likelihood of following the pathway of Cluster 2 in paid work but decreases the likelihood of following the pathway of Cluster 3.

Regarding the other three daily activities, relative to Cluster 1 of each daily activity, being diagnosed with breast cancer and skin cancer both increase the likelihood of following the pathway of household work for more than 15 hours per week, and decrease the likelihood of following the pathway of physical leisure at moderate to intensive level. Being diagnosed with breast cancer decreases the likelihood of following the pathway of passive leisure for more than 15 hours per week, whilst being diagnosed with skin cancer increases such likelihood.

\subsection{Association between paid work, household work, passive leisure and physical leisure}

Table 4 shows the association parameters $(\theta)$ between the pathways of paid work, household work, passive leisure and physical leisure. Most association parameters are significantly correlated, indicating the decision regarding the allocation of time across daily activities are dependent on each other. A positive value of an association parameter suggests the choices for any pair of daily activities tend to move together, whilst negative value means time allocated on one activity is at the cost of time allocated on the other activity. For instance, for the breast cancer sample (column 2), a woman who follows the pathway of Cluster 2 in paid work (full time paid work followed by unemployed), is less likely to follow the pathways of Cluster 2 (more than 15 hours per week) in household work $(\theta=-0.679)$, Cluster 2 (more than 15 hours) in passive leisure $(\theta=-0.973)$, and Cluster 2 (moderate to intensive level) in physical leisure with $(\theta=-0.343)$. 
Table 3. Multivariate Multinomial Logit for the pathways of time allocation

[Insert here]

Table 4. Estimates of the association parameters $(\theta)$ of MV-MNL model for the pathways of time allocation across daily activities [Insert here] 


\section{Robustness analysis}

So far we have found that neither breast cancer nor skin cancer has significantly influence on the pathways of time allocation in the long term. In this section, we perform two additional analysis to test the robustness of these results. We first look at the heterogenous effect of cancer severity on the pathways of time allocation. We then look at the change in time allocation before and after a cancer diagnosis; no change would suggest women return to their previous time use style soon after diagnosis.

\subsection{Association between cancer severity and pathways of time allocation}

For women diagnosed with breast cancer before age 55, no information is provided about whether they recovered from breast cancer after age 55. We labelled them as 'cured' if they stop reporting being diagnosed or treated with breast cancer after age 55; and 'non-cured' if they continue reporting being diagnosed or treated with breast cancer after age 55. Of 91 women diagnosed with breast cancer, 55 were considered as 'cured' and 36 as 'non-cured'.

Still, neither 'cured' nor 'non-cured' breast cancer has a significant impact on the pathways of time allocation (results are shown in Supplementary Table A3). The odds of following the pathways of Cluster 2 in paid work (full time paid work followed by part time paid work and unemployment) is 1.643 times greater in women living with a 'cured' breast cancer diagnosis than it is in women living without any cancer diagnosis; such odds however is 0.517 times less in women living with a 'non-cured' breast cancer diagnosis. Compared to women living without any cancer diagnosis, the odds of following pathway of moderate to intensive physical leisure is 0.852 times less in women living with a 'cured' breast cancer diagnosis and 1.12 times greater in women living with a 'non-cured' breast cancer diagnosis. 
For skin cancer, no information is provided in the ALSWH to distinguish between melanoma and non-melanoma. We differentiate the severity of skin cancer using the question: "In the past three years, have you had any of the following operations or procedures (chemotherapy or radiotherapy for any cancer)?" We labelled skin cancer as 'with chemotherapy or radiotherapy' if women reported being diagnosed with skin cancer (without other cancer diagnosed at the same time) and reported receiving chemotherapy or radiotherapy in the meantime; and 'without chemotherapy or radiotherapy' if women reported being diagnosed with skin cancer but not receiving chemotherapy or radiotherapy treatment. Of 486 women diagnosed with skin cancer, 31 were considered as 'with chemotherapy or radiotherapy', and 455 were considered as 'without chemotherapy or radiotherapy'.

Similar, skin cancer treated with and without 'chemotherapy or radiotherapy' has no significant effect on the pathways of time allocation (shown in Supplementary Table A4). The odds of following the pathway of physical leisure at moderate to intensive level is 0.941 times less in women 'without chemotherapy or radiotherapy' skin cancer diagnosis than it is in women living without any cancer diagnosis, and such odds is 1.653 times greater in women 'with chemotherapy or radiotherapy'. 


\subsection{Different definition of pathways: changes in time allocation before and after a cancer}

diagnosis

To investigate whether time allocation post a cancer diagnosis returns to pre-cancer time allocation, we focus on women who had no cancer in Wave 3 but were diagnosed in Wave 4 (as information on skin cancer was collected since Wave 4, skin cancer was not included in this analysis). Time allocation on daily activities in Wave 3 was considered as the benchmark (pre-cancer time allocation). The change of time allocation before and after breast cancer diagnosis was calculated as time use in post cancer waves (Wave 4 to 8 ) minus time use in Wave 3, i.e. W4-W3, W5-W3, W6-W3, W7-W3 and W8-W3. The control group is women living without any cancer diagnosis in all waves. Changes in time allocation were also calculated in this group with Wave 3 as benchmark. The numerical differences were then categorized into three groups: i) no change compared to Wave 3; ii) increased compared to Wave 3; and iii) decreased compared to wave 3.

Following the above analysis, we used sequence analysis to shape the pathways of categorical changes and clustered them into two groups for each daily activity: Cluster 1 -time use decreased after breast cancer diagnosis compared to Wave 3; and Cluster 2 - no change in time use after breast cancer diagnosis compared to Wave 3. Supplementary Table A5 summarizes the clusters of change in time allocation in both breast cancer group and noncancer group. In breast cancer group, compared to (pre-cancer) time use in Wave 3, 54\% of women follow the pathway of decreases time use on paid work after being diagnosed with breast cancer. Meanwhile, most women do not change time allocation on household work (75\%), passive leisure (93\%) and physical leisure (71\%) after breast cancer diagnosis. Among non-cancer group, $59 \%$ of women follow the pathway of decreasing time use on paid 
work after wave 3 . Most women do not change time allocation on other three daily activities after wave 3.

We then investigated the impact of being diagnosed with breast cancer on the pathways of changes in time allocation. As shown in Supplementary Table A6, the negative sign of all coefficients in the pathways of paid work, household work, and passive leisure indicates women diagnosed with breast cancer are less likely to maintain the time use pattern they had before breast cancer diagnosis. The odds of following the 'no change' pathways of paid work, household work and passive leisure are $0.901,0.778$ and 0.628 times less in women living with breast cancer diagnosis than it is in women living without any cancer diagnosis. However, these correlations did not reach significance.

\section{Discussion}

Our results suggest neither breast cancer nor skin cancer has a significant effect on the longterm pathways of time allocation. Our results were robust to severity of cancer ('cured' and 'non-cured' for breast cancer or with and without 'chemotherapy or radiotherapy' for skin cancer). However, following breast cancer diagnosis, women were less likely to maintain their pre-cancer's time use on paid work, household work and passive, though this effect is not significant.

The use of sequenced longitudinal data combined with multivariate multinomial logit is original and unique. We contribute to existing literature in three ways. First, in contrast to previous studies that only capture the time allocation at a given time point, we use a life course approach to explore the 'trajectories' of time allocation post a cancer diagnosis. This method provides a holistic overview of time allocation and highlights the underlying structure 
and heterogeneity in women's time allocation. Our results indicate women tend to keep the same time use patterns over time (Table 2). For instance, $28 \%$ women were continuously in the status of unemployment from Wave 4 to Wave 8 ; and $85 \%$ women never participate in physical leisure from Wave 4 to 8 . The quasi-fixity of time use patterns over time may imply that past time allocation choices might influence present time allocation, and deviation from such patterns generates opportunity cost(Hamermesh, 2005; Mullahy \& Robert, 2008).

Second, a life course perspective allows us to observe the long-term effects of a cancer diagnosis on time use. We assume cancer may have a 'cumulative disadvantages' i.e. its effect on time allocation is shown in a gradual and longitudinal manner. Our results, however, did not support this hypothesis. Being diagnosed with cancer seems to have no significant long-term effect on the pathways of time allocation. Whilst previous research suggests short-term and mid-term effects of cancer on employment(C. J. Bradley et al., 2002; Cathy J Bradley et al., 2005; Cathy J Bradley et al., 2007; David Candon, 2015; Sung Hee Jeon, 2014; Sung-Hee Jeon, 2016), our results suggest in the longer term such effect disappear.

Third, previous literature mainly focused on the effect of cancer on paid work. As time is finite and the opportunity cost of one activity is in the capacity to do another activity, only observing time allocation on work without accounting for the time allocation on other daily activities may result in an incomplete or even misleading results. Considering four daily activities simultaneously, our study therefore provides a comprehensive picture of time allocation after a cancer diagnosis. To accommodate inter-relationship among daily activities, we apply an MV-MNL model to predict the cluster membership. Our results show majority association parameters are significant (Table 4), implying the importance of considering four daily activities simultaneously. In separate analysis (not shown) in which multinomial logit 
model was performed on each daily activity separately, we found being diagnosed with breast cancer or skin cancer has a marginal significant effect on the pathway of household work. However, such significance disappeared when we applied the MV-MNL model. It indicates ignoring the inter-relationship among daily activities may lead to biased results.

This study is not exempt from limitations. Firstly, the results of our analysis are limited by the available data. Despite our data providing information on cancer types, the sample size for cervical cancer, lung cancer and bowl cancer are small. We therefore could not perform analysis in those cancer types. In addition, there is no detailed information on cancer stages. Different cancer stages may have heterogenous impact on the pathways of time allocations. In robustness analysis, we grouped breast cancer into 'cured' and 'non-cured', and skin cancer into with and without 'chemotherapy or radiotherapy'. It is worth noting that those classification may not adequately reveal cancer severity. Secondly, one disadvantage of sequence analysis is that it often requires individuals to have complete trajectories. That is, we only include women who completed the surveys in all waves; women who lost follow up were excluded (whilst TraMineR (Gabadinho, Ritschard, Studer, \& Müller, 2009) in R and multiple imputation package in STATA(Halpin, 2016) provide techniques to handle missing values, the quality of clustering with imputed missing values was poor in our data). Potentially, those who finished all waves may be healthier than those who were lost to follow-up. This selection bias may underestimate the effect of cancer on the pathways of time allocation. Thirdly, the sample size was limited when analysing the pathways of changes in time allocation before and after breast cancer diagnosis. Our data may thus lack the power to derive any potential significant effect. Lastly, the ALSWH survey is collected every three years. While this routine and ongoing data collection allows our analysis, the frequency means we may miss more short-term transitions in the intervening years thus underestimating the diversity of sequences on daily activities. However, the advantage of this survey, unlike 
most population-based surveys, is that it contains both information on time use and cancer diagnosis.

This study suggests avenue for future research. First, appropriate time allocation on labour market and non-labour market activities may be a key indicator of successful aging and high quality of health and life satisfaction(Gauthier \& Smeeding, 2003). As wellbeing may become priority post a cancer diagnosis, future work may investigate the relationship between time allocation and wellbeing. Second, a cancer diagnosis may change individuals' preference for time allocation. Preference for time allocation reveals individuals' desired priorities on daily activities, their ideal life styles and life goals (Dahm, Glomb, Manchester, \& Leroy, 2015; Sheldon \& Elliot, 1999). Understanding the preference for time allocation may reveal individuals' needs and unmet needs on life domains.

In summary, our results suggest being diagnosed with breast cancer or skin cancer has no significant long-term effect on the pathways of time allocation. Future work should explore the relationship between time allocation and wellbeing, and the preference for time allocation. 


\section{References}

Anyadike-Danes, M., and McVicar, D. (2010). My brilliant career: Characterizing the early labor market trajectories of British women from generation X. Sociological Methods \& Research, 38, 482-512.

Australia Bureau of Statistics. (2019). Australia Government Cancer. Retrieved from https://canceraustralia.gov.au/affected-cancer/what-cancer/cancer-australia-statistics

Australian Bureau of Statistics. (2001). Labour statistics: Concepts, sources and methods. Retrieved fromhttp://www.ausstats.abs.gov.au/ausstats/free.nsf/Lookup/819D9201B77786E7CA256A A0000667C3/\$File/61020_2001.pdf

Bel, K., \& Paap, R. (2014). A multivariate model for multinomial choices. Retrieved from

Bradley, C. J. (2015). Economic recovery: A measure of the quality of cancer treatment and survivorship? Cancer, 121(24), 4282-4285.

Bradley, C. J., Bednarek, H. L., \& Neumark, D. (2002). Breast cancer and women's labor supply. Health Services Research, 37(5), 1309-1328.

Bradley, C. J., Neumark, D., Bednarek, H. L., \& Schenk, M. (2005). Short-term effects of breast cancer on labor market attachment: results from a longitudinal study. Journal of Health Economics, 24(1), 137-160.

Bradley, C. J., Neumark, D., Luo, Z., \& Schenk, M. (2007). Employment and cancer: findings from a longitudinal study of breast and prostate cancer survivors. Cancer investigation, 25(1), 4754.

Brazier, J., Roberts, J., \& Deverill, M. J. J. o. h. e. (2002). The estimation of a preference-based measure of health from the SF-36. 21(2), 271-292.

Candon, D. (2015). The Effects of Cancer on Older Workers in the English Labour Market. Economics and Human Biology, 18, 74-84. doi:http://dx.doi.org/10.1016/j.ehb.2015.04.001

Candon, D. (2015). The effects of cancer on older workers in the English labour market. Economics \& Human Biology, 18, 74-84.

Caragea, N. J. R. R. d. E. (2009). Time Allocation in Economics and the Implications for Economic Development. 28(2).

Dahm, P. C., Glomb, T. M., Manchester, C. F., \& Leroy, S. (2015). Work-family conflict and selfdiscrepant time allocation at work. Journal of Applied Psychology, 100(3), 767.

Dannefer, D. (2003). Cumulative advantage/disadvantage and the life course: Cross-fertilizing age and social science theory. The Journals of Gerontology Series B: Psychological Sciences and Social Sciences, 58(6), S327-S337.

Gabadinho, A., Ritschard, G., Studer, M., \& Müller, N. S. (2009). Mining sequence data in R with the TraMineR package: A users guide for version 1.2. Geneva: University of Geneva.

Gauthier, A. H., \& Smeeding, T. M. (2003). Time use at older ages: Cross-national differences. Research on Aging, 25(3), 247-274.

Gimenez-Nadal, J. I., \& Molina, J. A. (2015). Health status and the allocation of time: Cross-country evidence from Europe. Economic Modelling, 46, 188-203.

Gimenez-Nadal, J. I., \& Molina, J. A. (2016). Health inequality and the uses of time for workers in Europe: policy implications. IZA Journal of European Labor Studies, 5(1), 2.

Gimenez-Nadal, J. I., \& Ortega-Lapiedra, R. (2013). Health status and time allocation in Spain. Applied Economics Letters, 20(15), 1435-1439.

Halpin, B. (2016). Multiple imputation for categorical time series. Stata Journal, 16(3), 590-612.

Hamermesh, D. S. (2005). Routine. European Economic Review, 49(1), 29-53.

Hamermesh, D. S., \& Pfann, G. A. (2004). The economics of time use: Emerald Group Publishing Limited.

Hennig, C., Liao, T.F. (2010). Comparing latent class and dissimilarity based clustering for mixed type variables with application to social stratification. Technical report. 
Hewitt, M., Greenfield, S., \& Stovall, E. (2005). From cancer patient to cancer survivor: lost in transition: National Academies Press.

Hoem, J. M., \& Kreyenfeld, M. (2006). Anticipatory analysis and its alternatives in life-course research: Part 1: Education and first childbearing. Demographic Research, 15, 461-484.

Hoven, H., Dragano, N., Blane, D., \& Wahrendorf, M. (2017). Early Adversity and Late Life Employment History-A Sequence Analysis Based on SHARE. Work, Aging and Retirement, 4(3), 238-250.

Hubert, L., Arabie, P. (1985). Comparing partitions. Journal of classification, 2, 193-218.

Jeon, S. H. (2014). The Effects of Cancer on Employment and Earnings of Cancer Survivors. In: Statistics Canada, Analytical Studies Branch, Analytical Studies Branch Research Paper Series.

Jeon, S. H. (2016). The Long-Term Effects of Cancer on Employment and Earnings. Health economics.

Kaufman, L., Rousseeuw, P.J. (2009). Finding groups in data: an introduction to cluster analysis: John Wiley \& Sons.

Kiasuwa Mbengi, R., Otter, R., Mortelmans, K., Arbyn, M., Van Oyen, H., Bouland, C., \& de Brouwer, C. (2016). Barriers and opportunities for return-to-work of cancer survivors: time for action-rapid review and expert consultation. Systematic Reviews, 5, 35.

Leufstadius, C., \& Eklund, M. (2008). Time use among individuals with persistent mental illness: Identifying risk factors for imbalance in daily activities. Scandinavian Journal of Occupational Therapy, 15(1), 23-33.

Lomax, C. L., Brown, R. G., \& Howard, R. J. (2004). Measuring disability in patients with neurodegenerative disease using the 'Yesterday Interview'. International journal of geriatric psychiatry, 19(11), 1058-1064.

Mackenzie, C.R. (2014). 'It is hard for mums to put themselves first': how mothers diagnosed with breast cancer manage the sociological boundaries between paid work, family and caring for the self. Social Science \& Medicine, 117, 96-106.

Maunsell, E., Brisson, C., Dubois, L., Lauzier, S., \& Fraser, A. (1999). Work problems after breast cancer: an exploratory qualitative study. Psycho-Oncology: Journal of the Psychological, Social and Behavioral Dimensions of Cancer, 8(6), 467-473.

Moran, J. R., \& Short, P. F. (2014). Does cancer reduce labor market entry? Evidence for prime-age females. Medical Care Research \& Review, 71(3), 224-242.

Moran, J. R., Short, P. F., \& Hollenbeak, C. S. (2011). Long-term employment effects of surviving cancer. Journal of Health Economics, 30(3), 505-514.

Mullahy, J., \& Robert, S. A. (2008). No time to lose? Time constraints and physical activity. Retrieved from

Norman, R., Viney, R., Brazier, J., Burgess, L., Cronin, P., King, M., . . Street, D. J. M. D. M. (2014). Valuing SF-6D health states using a discrete choice experiment. 34(6), 773-786.

Pagán, R. (2013). Time allocation of disabled individuals. Social Science \& Medicine, 84, 80-93.

Pentland, W., Harvey, A., Smith, T., \& Walker, J. (1999). The impact of spinal cord injury on men's time use. Spinal cord, 37(11).

Podor, M., \& Halliday, T. J. (2012). Health status and the allocation of time. Health Economics, 21(5), 514-527.

Pryce, J., Munir, F., \& Haslam, C. (2007). Cancer survivorship and work: symptoms, supervisor response, co-worker disclosure and work adjustment. Journal of Occupational Rehabilitation, 17(1), 83-92.

Sheldon, K. M., \& Elliot, A. J. (1999). Goal striving, need satisfaction, and longitudinal well-being: the self-concordance model. Journal of personality and social psychology, 76(3), 482.

Shimitras, L., Fossey, E., \& Harvey, C. (2003). Time use of people living with schizophrenia in a North London catchment area. British Journal of Occupational Therapy, 66(2), 46-54.

Studer, M. (2013). WeightedCluster library manual: A practical guide to creating typologies of trajectories in the social sciences with $\mathrm{R}$. 
Studer, M., Ritschard, G. (2016). What matters in differences between life trajectories: A comparative review of sequence dissimilarity measures. Journal of the Royal Statistical Society: Series A (Statistics in Society), 179, 481-511.

World Health Organization (WHO). (2010.). Retrieved from https://www.who.int/dietphysicalactivity/factsheet_adults/en/

Young, A. F., Dobson, A. J., Lee, C., Byles, J., Bryson, L., Warner-Smith, P., \& Brown, W. J. (2005). Cohort Profile: The Australian Longitudinal Study on Women's Health. International Journal of Epidemiology, 34(5), 987-991. doi:10.1093/ije/dyi098 \%J International Journal of Epidemiology

\section{Acknowledgement}

The authors would like to thank the two anonymous reviewers for their constructive and insightful comments. The authors acknowledge colleagues in Health Economic Research Unit, University of Aberdeen for their valuable comments on this paper. The University of Aberdeen and the Chief Scientist Office of the Scottish Government Health and Social Care Directorates fund the Health Economics Research Unit (HERU). The research on which this paper is based was conducted as part of the Australian Longitudinal Study on Women's Health by the University of Queensland and the University of Newcastle. We are grateful to the Australian Government Department of Health for funding and to the women who provided the survey data.

\section{Authors Contribution}

NG designed the study, collected data, and drafted the manuscript; NG and NK involved in data analysis and interpretation. MR and NK critically reviewed and revised the manuscript for important intellectual content. RN and SR provided comments and revision on manuscript.

\section{Funding}

NG is funded by the Aberdeen-Curtin Joint Studentship (University of Aberdeen Development Trust) and the Elphinstone Scholarship Scheme.

\section{Competing interest}

None 
Table 1. Time allocation and socioeconomic characteristics by Wave

\begin{tabular}{|c|c|c|c|c|c|c|}
\hline $\mathrm{N}=3,288$ & $\begin{array}{l}\text { Wave3 } \\
\text { (2001) }\end{array}$ & $\begin{array}{l}\text { Wave4 } \\
\text { (2004) }\end{array}$ & $\begin{array}{l}\text { Wave5 } \\
(2007)\end{array}$ & $\begin{array}{l}\text { Wave6 } \\
(2010)\end{array}$ & $\begin{array}{l}\text { Wave7 } \\
\text { (2013) }\end{array}$ & $\begin{array}{l}\text { Wave8 } \\
(2016)\end{array}$ \\
\hline \multicolumn{7}{|l|}{ Paid work } \\
\hline Unemployed & 19.09 & 24.27 & 28.62 & 38.41 & 54.20 & 69.10 \\
\hline Part time & 35.73 & 37.77 & 38.93 & 37.07 & 30.29 & 23.18 \\
\hline Full time & 45.18 & 37.96 & 32.45 & 24.51 & 15.51 & 7.73 \\
\hline \multicolumn{7}{|l|}{ Household work } \\
\hline$\leq 15$ hours/week & 51.88 & 56.90 & 51.52 & 52.74 & 51.00 & 52.25 \\
\hline$>15$ hours/week & 48.12 & 43.10 & 48.48 & 47.26 & 49.00 & 47.75 \\
\hline \multicolumn{7}{|l|}{ Passive leisure } \\
\hline 1-15 hours/week & 70.37 & 66.12 & 63.69 & 60.16 & 57.94 & 52.86 \\
\hline$>15$ hours/week & 29.63 & 33.88 & 36.31 & 39.84 & 42.06 & 47.14 \\
\hline \multicolumn{7}{|l|}{ Physical leisure } \\
\hline Zero & 77.11 & 75.91 & 71.50 & 72.84 & 74.18 & 71.59 \\
\hline Low & 9.93 & 8.58 & 9.85 & 9.03 & 9.55 & 11.16 \\
\hline Moderate & 5.43 & 5.84 & 7.60 & 6.78 & 6.81 & 6.784 \\
\hline Intensive & 7.54 & 9.67 & 11.04 & 11.34 & 9.46 & 10.40 \\
\hline Age & 52.40 & 55.38 & 58.38 & 61.42 & 64.67 & 67.67 \\
\hline (Mean (SD)) & $(1.47)$ & $(1.48)$ & $(1.46)$ & $(1.46)$ & $(1.47)$ & $(1.47)$ \\
\hline Married (Yes) & 77.36 & 76.23 & 74.87 & 72.89 & 70.41 & 68.04 \\
\hline \multicolumn{7}{|l|}{ Education } \\
\hline \multicolumn{7}{|l|}{ No formal } \\
\hline Intermediate & 46.55 & 46.55 & 46.55 & 46.55 & 46.55 & 46.55 \\
\hline Occupation & 21.93 & 21.93 & 21.93 & 21.93 & 21.93 & 21.93 \\
\hline \multicolumn{7}{|l|}{ University and } \\
\hline higher & 19.35 & 19.35 & 19.35 & 19.35 & 19.35 & 19.35 \\
\hline SF-6D & 0.61 & 0.60 & 0.61 & 0.60 & 0.60 & 0.58 \\
\hline (Mean(SD)) & $(0.22)$ & $(0.22)$ & $(0.22)$ & $(0.22)$ & $(0.22)$ & $(0.22)$ \\
\hline \multicolumn{7}{|l|}{ General health } \\
\hline Poor & 0.93 & 0.76 & 0.64 & 0.76 & 0.79 & 0.79 \\
\hline Fair & 8.37 & 8.59 & 8.63 & 8.81 & 9.35 & 9.46 \\
\hline Good & 36.56 & 35.59 & 33.86 & 37.47 & 37.16 & 37.38 \\
\hline Very good & 42.02 & 41.58 & 42.15 & 40.64 & 41.30 & 40.95 \\
\hline Excellent & 12.13 & 13.47 & 14.72 & 12.32 & 11.39 & 11.41 \\
\hline \multicolumn{7}{|l|}{ Number of } \\
\hline $\begin{array}{l}\text { diseases } \\
\text { (Mean (SD)) }\end{array}$ & $\begin{array}{l}0.87 \\
(1.08)\end{array}$ & $\begin{array}{l}1.04 \\
(1.20)\end{array}$ & $\begin{array}{l}1.17 \\
(1.29)\end{array}$ & $\begin{array}{l}1.29 \\
(1.40)\end{array}$ & $\begin{array}{l}1.23 \\
(1.29)\end{array}$ & $\begin{array}{l}3 . / 4 \\
(1.57)\end{array}$ \\
\hline \multicolumn{7}{|l|}{ Providing care } \\
\hline & 75.06 & 69.95 & 70.89 & 71.78 & 73.87 & 76.58 \\
\hline \multicolumn{7}{|l|}{ Once every few } \\
\hline often & 5.43 & 6.36 & 6.69 & 6.36 & 5.29 & 4.65 \\
\hline \multicolumn{7}{|l|}{ Once or several } \\
\hline Everyday & 5.59 & 7.09 & 7.24 & 8.09 & 8.88 & 8.18 \\
\hline \multicolumn{7}{|l|}{ Number of } \\
\hline people living & 1.54 & 1.31 & 1.12 & 1.06 & 1.05 & 0.98 \\
\hline with (Mean (SD)) & $(1.07)$ & $(0.96)$ & $(0.77)$ & $(0.74)$ & $(0.91)$ & $(0.85)$ \\
\hline
\end{tabular}

§Age, SF-6D, number of diseases and number of people living with were shown as mean value with standard deviation (SD) in brackets. Other variables were shown as percentage. Information on education was collected only in Wave 1. 'Occupation' in education means hairdresser, chef, child care, etc. SF-6D was calculated based on SF-36 in ALSWH. Scores and utility weights of SF-6D were based on two previous studies, based in the UK 
and Australia respectively (Brazier, Roberts, \& Deverill, 2002; Norman et al., 2014). 'Number of people living with' means the number of children, parents, relatives or other adults live with respondents.

Table 2. Distribution of clusters among four daily activities

\begin{tabular}{llc} 
& Daily activities & $\begin{array}{c}\text { Percentage } \\
\text { (N=3,288) }\end{array}$ \\
\hline Cluster 1 & Paid work & Unemployment only \\
Cluster 2 & Mixed: Full time (W4 to W6)+Part time (W7)+Unemployment (W8) & $27.71 \%$ \\
Cluster 3 & Mixed: Part time (W4 to W6)+Unemployment (W7 to W8) & $32.30 \%$ \\
& Household work & $39.99 \%$ \\
Cluster 1 & Household work $\leq$ 15 hour per week & \\
Cluster 2 & Household work>15 hours per week & $53.28 \%$ \\
& Passive leisure & $46.72 \%$ \\
Cluster 1 & Passive leisure 1-15 hours per week & \\
Cluster 2 & Passive leisure >15 hours per week & $62.07 \%$ \\
& Physical leisure & $37.93 \%$ \\
Cluster 1 & Physical leisure (zero) & \\
Cluster 2 & Physical leisure (moderate to intensive) & $82.15 \%$ \\
\hline
\end{tabular}


Table 3. Multivariate Multinomial Logit for the pathways of time allocation

\begin{tabular}{|c|c|c|c|c|}
\hline & $\begin{array}{l}\text { Breast Cancer } \\
\text { MLE (SE) }\end{array}$ & OR (CI) & $\begin{array}{l}\text { Skin Cancer } \\
\text { MLE (SE) }\end{array}$ & OR (CI) \\
\hline \multicolumn{5}{|l|}{ Paid work } \\
\hline \multicolumn{5}{|l|}{ Cluster 1: Unemployement:5 (reference) } \\
\hline Cluster 2: Full time:3- Part time :1-Unemployment: 1 & $\begin{array}{l}0.180 \\
(0.288)\end{array}$ & $\begin{array}{l}1.198 \\
(0.681-2.109)\end{array}$ & $\begin{array}{l}0.184 \\
(0.128)\end{array}$ & $\begin{array}{l}1.203 \\
(0.936-1.546)\end{array}$ \\
\hline Cluster 3: Part time:3-Unemployment:2 & $\begin{array}{l}0.278 \\
(0.301)\end{array}$ & $\begin{array}{l}1.320 \\
(0.732-2.380)\end{array}$ & $\begin{array}{l}-0.098 \\
(0.142)\end{array}$ & $\begin{array}{l}0.907 \\
(0.685-1.120)\end{array}$ \\
\hline \multicolumn{5}{|l|}{ Household work } \\
\hline \multicolumn{5}{|l|}{ Cluster 1: household work $\leq 15$ hour per week (reference) } \\
\hline Cluster 2: household work >15 hours per week & $\begin{array}{l}0.181 \\
(0.227)\end{array}$ & $\begin{array}{l}1.198 \\
(0.768-1.872)\end{array}$ & $\begin{array}{l}0.139 \\
(0.105)\end{array}$ & $\begin{array}{l}1.149 \\
(0.936-1.410)\end{array}$ \\
\hline \multicolumn{5}{|l|}{ Passive leisure } \\
\hline \multicolumn{5}{|l|}{ Cluster 1: passive leisure 1-15 hours per week (reference) } \\
\hline Cluster 2: passive leisure $>15$ hours per week & $\begin{array}{l}-0.378 \\
(0.232)\end{array}$ & $\begin{array}{l}0.685 \\
(0.435-1.079)\end{array}$ & $\begin{array}{l}0.177 \\
(0.105)\end{array}$ & $\begin{array}{l}1.193 \\
(0.972-1.464)\end{array}$ \\
\hline \multicolumn{5}{|l|}{ Physical leisure } \\
\hline Cluster 2: physical leisure (moderate to intensive) & $\begin{array}{l}-0.028 \\
(0.286)\end{array}$ & $\begin{array}{l}0.972 \\
(0.555-1.703)\end{array}$ & $\begin{array}{l}-0.027 \\
(0.126)\end{array}$ & $\begin{array}{l}0.973 \\
(0.761-1.245)\end{array}$ \\
\hline Number of individuals & 2802 & & 3186 & \\
\hline Number of parameters & 94 & & 94 & \\
\hline Log-likelihood & -7604.3 & & -8693.3 & \\
\hline $\mathrm{BIC}$ & 16085.1 & & 18275.2 & \\
\hline
\end{tabular}

Notes:

Covariates include age, marriage, education, SF-6D, general health, number of chronic diseases, whether providing care, and number of people living with. Full results are available on request.

There were 2711 women living without cancer in breast cancer-control group and 2700 women living without cancer in the skin cancer-control group.

Standard errors (SE) of coefficient and confidence interval (CI) of odds ratio in parentheses.

${ }^{*} \mathrm{p}<0.1, * * \mathrm{p}<0.05, * * * \mathrm{p}<0.01$. 
Table 4. Estimates of the association parameters $(\theta)$ of MV-MNL model for the pathways of time allocation across daily activities

\begin{tabular}{|c|c|c|c|c|c|}
\hline Breast Cancer & Paid work & & Household work & Passive leisure & Physical leisure \\
\hline & Cluster 2 & Cluster 3 & Cluster 2 & Cluster 2 & Cluster 2 \\
\hline Household work (Cluster 2) & $-0.679(0.112) * * *$ & $-0.122(0.101)$ & & & \\
\hline Passive leisure (Cluster 2) & $-0.973(0.114)^{* * *}$ & $-0.497(0.100)^{* * *}$ & $0.417(0.085)^{* * *}$ & & \\
\hline Physical leisure (Cluster 2) & $-0.343(0.148) * * *$ & $-0.018(0.132)^{* * *}$ & $-0.198(0.109)^{*}$ & $-0.492(0.115)^{* * *}$ & \\
\hline \multirow[t]{2}{*}{ Skin Cancer } & Paid work & & Household work & Passive leisure & Physical leisure \\
\hline & Cluster 2 & Cluster 3 & Cluster 2 & Cluster 2 & Cluster 2 \\
\hline Household work (Cluster 2) & $-0.688(0.104) * * *$ & $-0.144(0.094)$ & & & \\
\hline Passive leisure (Cluster 2) & $-0.955(0.107) * * *$ & $-0.498(0.093)^{* * *}$ & $0.371(0.079)^{* * *}$ & & \\
\hline Physical leisure (Cluster 2) & $-0.415(0.137) * * *$ & $-0.072(0.121)$ & $-0.185(0.100)^{*}$ & $-0.486(0.105)^{* * *}$ & \\
\hline
\end{tabular}

*Standard errors in parentheses. As the association parameters are symmetric, only the lower triangular matrix is given. Cluster 1 in each daily activity is the reference group. 
Figure 1. The trends of time allocation from wave 3 to 8

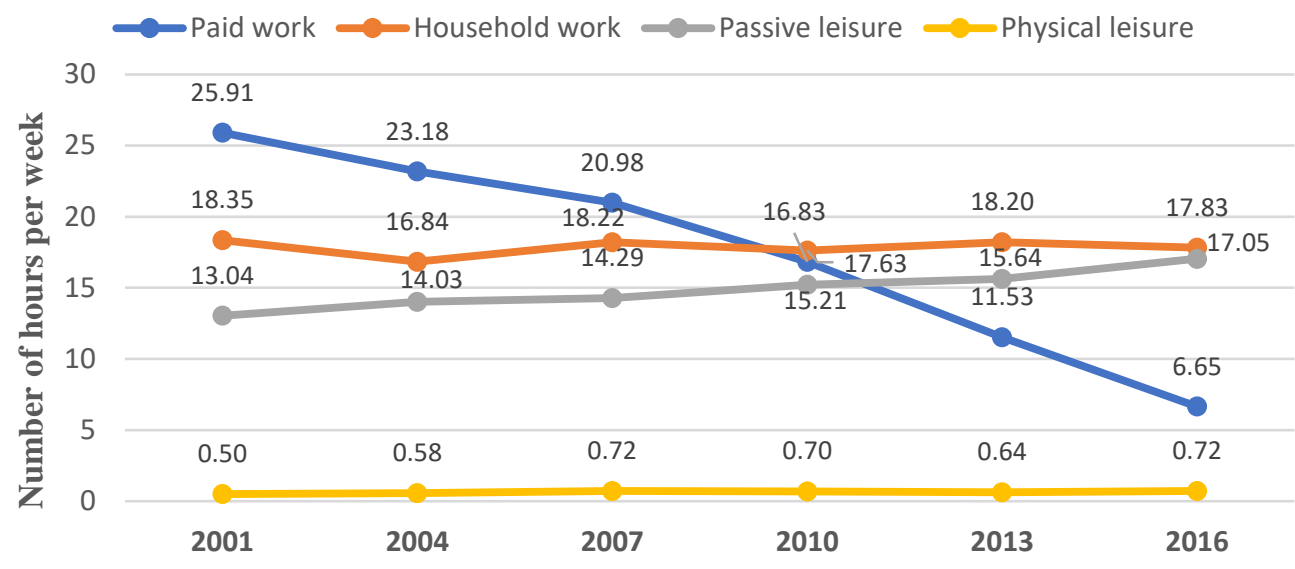


Figure 2. Sequence frequency plots on daily activities

Panel A: Pathways of paid work and household work
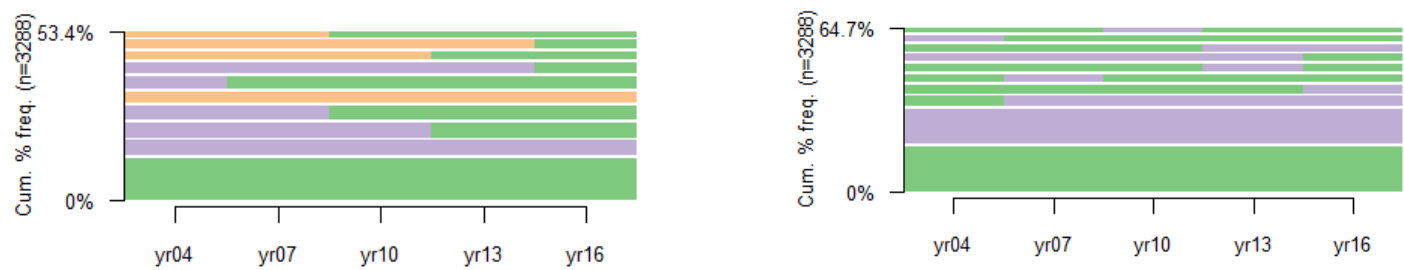

$\square$ Unemployment $\square$ Full-time

$\square=15$ hours per week

Part-time

Panel B: Pathways of passive leisure and physical leisure
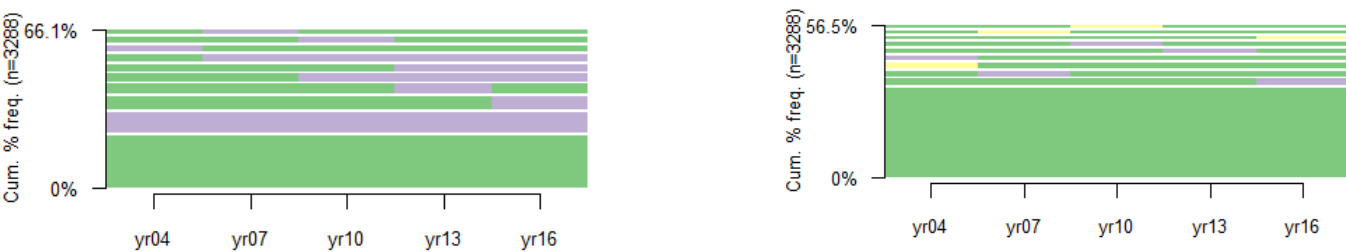
Figure 3. Distribution of clusters among non-cancer group, breast cancer group and skin cancer group

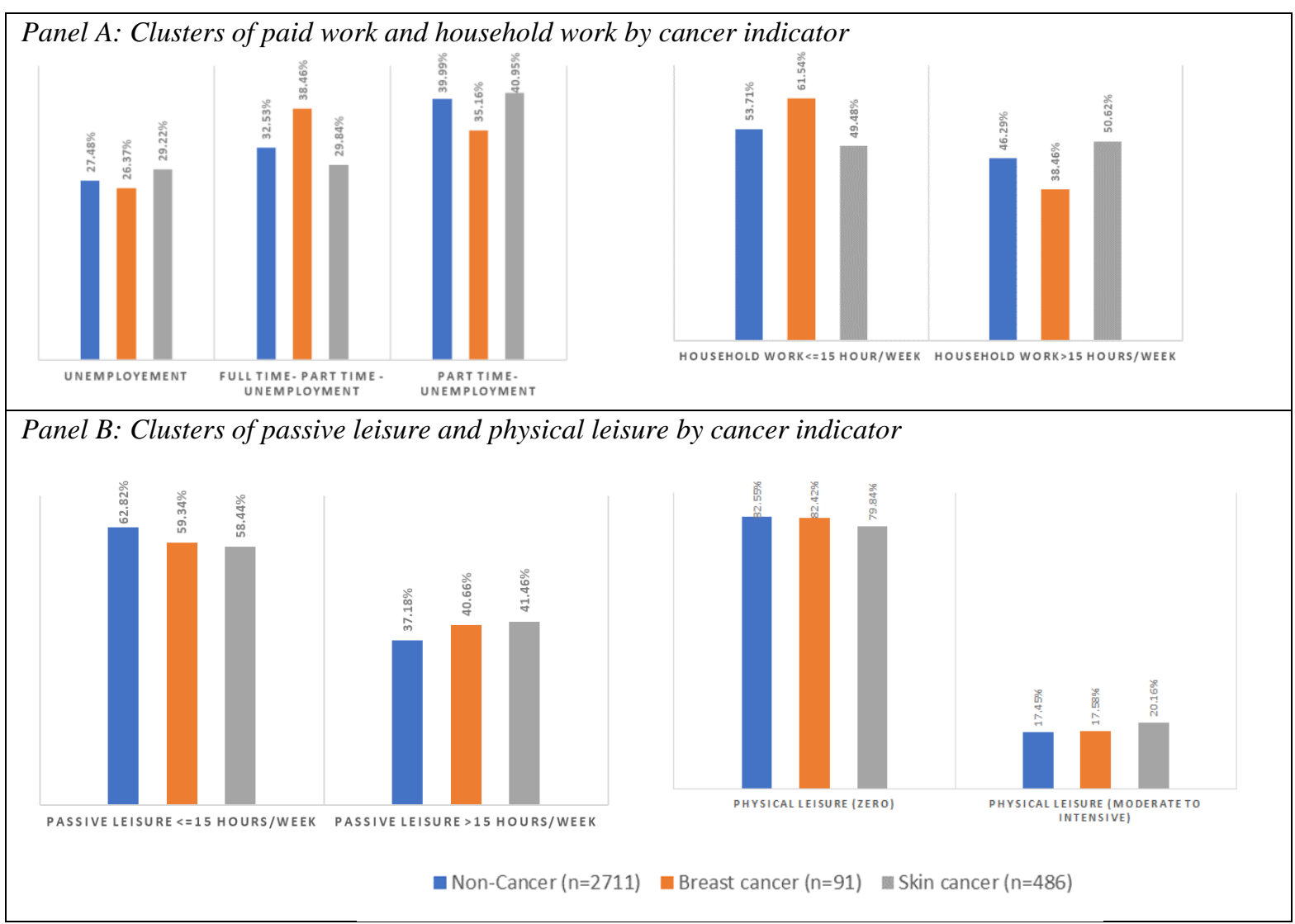




\section{Supplementary Material}

\section{Table A1. Time use questions in ALSWH}

In a USUAL WEEK, how much time in total do you spend doing the following things?

\begin{tabular}{|c|c|c|c|c|c|c|c|}
\hline & $\begin{array}{l}\text { I don't } \\
\text { do this } \\
\text { activity }\end{array}$ & $\begin{array}{l}1-15 \\
\text { hours }\end{array}$ & $\begin{array}{l}16-24 \\
\text { hours }\end{array}$ & $\begin{array}{l}25-34 \\
\text { hours }\end{array}$ & $\begin{array}{l}35-40 \\
\text { hours }\end{array}$ & $\begin{array}{l}41-48 \\
\text { hours }\end{array}$ & $\begin{array}{l}49 \\
\text { hours } \\
\text { or more }\end{array}$ \\
\hline Full time paid work & $\cdot$ & $\bullet$ & $\bullet$ & $\bullet$ & $\bullet$ & $\bullet$ & $\cdot$ \\
\hline Part time paid work & $\bullet$ & $\bullet$ & $\bullet$ & $\bullet$ & $\bullet$ & $\bullet$ & • \\
\hline Casual paid work & $\bullet$ & $\bullet$ & $\bullet$ & $\bullet$ & $\bullet$ & $\bullet$ & $\bullet$ \\
\hline Home duties & - & - & - & $\bullet$ & - & - & $\bullet$ \\
\hline Work without pay & $\bullet$ & $\bullet$ & $\bullet$ & $\bullet$ & $\bullet$ & $\bullet$ & $\bullet$ \\
\hline Looking for work & $\bullet$ & $\bullet$ & $\bullet$ & • & $\bullet$ & $\bullet$ & $\bullet$ \\
\hline Unpaid voluntary work & - & • & - & • & - & • & - \\
\hline Active leisure & - & - & - & $\bullet$ & - & - & - \\
\hline Passive leisure & • & • & $\bullet$ & • & $\bullet$ & $\bullet$ & $\bullet$ \\
\hline Studying & - & $\bullet$ & $\bullet$ & $\bullet$ & $\bullet$ & $\bullet$ & $\bullet$ \\
\hline Socialising & • & • & • & • & • & • & • \\
\hline $\begin{array}{l}\text { Buying goods and/or } \\
\text { services }\end{array}$ & • & • & • & • & • & • & • \\
\hline
\end{tabular}




\section{Table A2. Cluster cut-off criteria for cluster analysis}

\begin{tabular}{clll} 
Cluster solution & $\begin{array}{l}\text { Average } \\
\text { Silhouette Width }\end{array}$ & $\begin{array}{l}\text { Point Biserial } \\
\text { Correlation }\end{array}$ & Hubert's Gamma \\
\hline Paid work & & & \\
2 & 0.39 & 0.53 & 0.66 \\
3 & 0.45 & 0.64 & 0.78 \\
4 & 0.43 & 0.64 & 0.84 \\
5 & 0.42 & 0.63 & 0.88
\end{tabular}

Household work

$\begin{array}{llll}2 & 0.56 & 0.74 & 0.92 \\ 3 & 0.47 & 0.69 & 0.90 \\ 4 & 0.47 & 0.66 & 0.91 \\ 5 & 0.50 & 0.65 & 0.95\end{array}$

Passive leisure

$\begin{array}{llll}2 & 0.55 & 0.72 & 0.91 \\ 3 & 0.46 & 0.68 & 0.90 \\ 4 & 0.44 & 0.63 & 0.89 \\ 5 & 0.46 & 0.63 & 0.91\end{array}$

Physical leisure

$\begin{array}{llll}2 & 0.55 & 0.73 & 0.90 \\ 3 & 0.50 & 0.74 & 0.87 \\ 4 & 0.44 & 0.72 & 0.84 \\ 5 & 0.43 & 0.69 & 0.82\end{array}$

* The higher values of those measurements indicate higher similarity within one group and higher dissimilarity between groups. For instance, Average Silhouette Width (ASW) above 0.5 is considered to indicate a good structure(Studer, 2013). Household work, passive leisure and physcial leisure all have clusters with ASW above 0.5. Paid work has a reatively weak clustering, with highest ASW at 0.45 . To test whether the weak clustering is due to sampling size, we tried to cluster paid work on a larger sample size $(n=5420)$, which created the highest ASW value at 0.48 . Note that even though those measurements provide a benchmark to choose the best cluster solution, they are from a statistic standpoint. The final cluster solution should be based on the consideration of both statisictic results and practical meaning of clusters. 
Table A3. Multivariate Multinomial Logit for the pathways of time allocation by cancer severity (breast cancer)

\begin{tabular}{|c|c|c|c|c|}
\hline \multirow{2}{*}{ Paid work } & \multicolumn{2}{|c|}{ Breast cancer ('cured') } & \multicolumn{2}{|c|}{ Breast cancer ('non-cured') } \\
\hline & MLE (SE) & $\mathrm{OR}(\mathrm{CI})$ & MLE (SE) & $\mathrm{OR}(\mathrm{CI})$ \\
\hline \multicolumn{5}{|l|}{ Cluster 1: Unemployement:5 (reference) } \\
\hline \multirow[t]{2}{*}{ Cluster 2: Full time:3- Part time :1-Unemployment:1 } & 0.497 & 1.643 & -0.659 & 0.517 \\
\hline & $(0.333)$ & $(0.855-3.157)$ & $(0.628)$ & $(0.151-1.773)$ \\
\hline \multirow[t]{2}{*}{ Cluster 3: Part time:3-Unemployment:2 } & 0.014 & 1.014 & 0.620 & 1.859 \\
\hline & $(0.380)$ & $(0.481-2.140)$ & $(0.481)$ & $(0.725-4.768)$ \\
\hline \multicolumn{5}{|l|}{ Household work } \\
\hline \multicolumn{5}{|l|}{ Cluster 1: household work $\leq 15$ hour per week (reference) } \\
\hline \multirow[t]{2}{*}{ Cluster 2: household work >15 hours per week } & 0.082 & 1.086 & 0.275 & 1.316 \\
\hline & $(0.296)$ & $(0.608-1.938)$ & $(0.354)$ & $(0.657-2.636)$ \\
\hline \multicolumn{5}{|l|}{ Passive leisure } \\
\hline \multicolumn{5}{|l|}{ Cluster 1: passive leisure 1-15 hours per week (reference) } \\
\hline \multirow[t]{2}{*}{ Cluster 2: passive leisure $>15$ hours per week } & -0.475 & 0.622 & -0.213 & 0.808 \\
\hline & $(0.298)$ & $(0.347-1.114)$ & $(0.365)$ & $(0.395-1.652)$ \\
\hline \multicolumn{5}{|l|}{ Physical leisure } \\
\hline \multicolumn{5}{|l|}{ Cluster 1: physical leisure (zero) (reference) } \\
\hline \multirow[t]{2}{*}{ Cluster 2: physical leisure (moderate to intensive) } & -0.160 & 0.852 & 0.114 & 1.120 \\
\hline & $(0.357)$ & $(0.423-1.716)$ & $(0.466)$ & $(0.450-2.792)$ \\
\hline Number of individuals & \multicolumn{4}{|c|}{2802} \\
\hline Number of parameters & \multicolumn{4}{|c|}{99} \\
\hline Log-likelihood & \multicolumn{4}{|c|}{-7602.1} \\
\hline $\mathrm{BIC}$ & \multicolumn{4}{|c|}{16127.3} \\
\hline
\end{tabular}


Table A4. Multivariate Multinomial Logit for the pathways of time allocation by cancer severity (skin cancer)

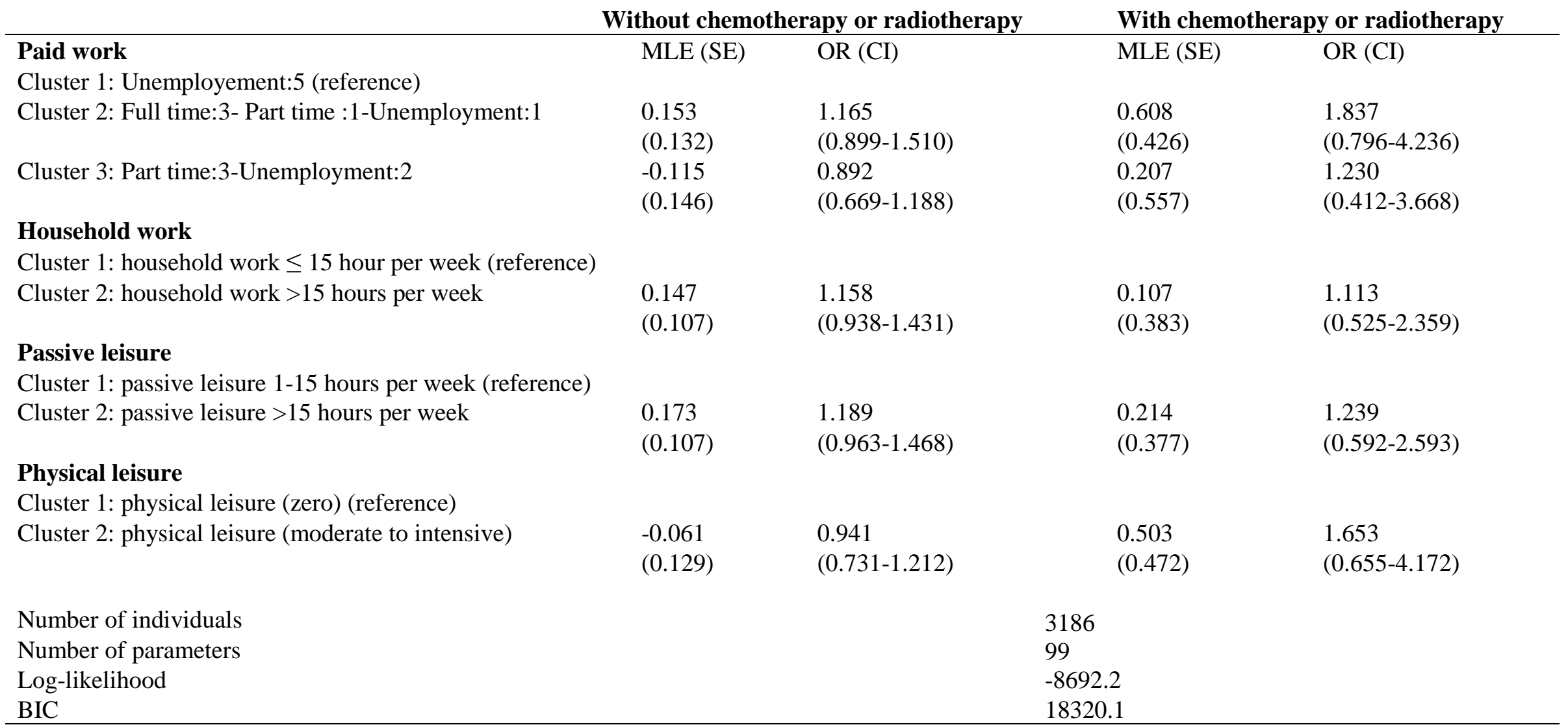

Covariates include age, marriage, education, SF-6D, general health, number of chronic diseases, whether providing care, and number of people living with. Full results are available on request.

Standard errors (SE) of coefficient and confidence interval (CI) of odds ratio in parentheses.

$* \mathrm{p}<0.1, * * \mathrm{p}<0.05, * * * \mathrm{p}<0.01$ 
Table A5. Clusters of change in time allocation on four daily activities 
Table A6. The effects of being diagnosed with a breast cancer on the pathways of change in time allocation

MLE (SE) OR (CI)

\section{Paid work}

Cluster 1: Decreased in all waves (reference)

Cluster 2: No change

$-0.104 \quad 0.901$

$(0.237) \quad(0.567-1.433)$

Household work

Cluster 1: Decreased in all waves (reference)

Cluster 2: No change

$-0.251 \quad 0.778$

$(0.258) \quad(0.469-1.291)$

Passive leisure

Cluster 1: Decreased in all waves (reference)

Cluster 2: No change

$\begin{array}{ll}-0.465 & 0.628 \\ (0.353) & (0.314-1.256)\end{array}$

Physical leisure

Cluster 1: Decreased in all waves (reference)

Cluster 2: No change

$0.352 \quad 1.423$

$(0.259) \quad(0.856-2.365)$

Number of individuals $\quad 3889$

Log-likelihood $\quad-8410.05$

Notes:

As outcomes are all binary, multivariate probit was used to perform this analysis.

Covariates include: age, marriage, education, SF-6D, general health, number of chronic diseases, whether providing care, and number of people living with.

Standard errors (SE) of coefficient and confidence interval (CI) of odds ratio in parentheses.

$* \mathrm{p}<0.1, * * \mathrm{p}<0.05, * * * \mathrm{p}<0.01$. 